\title{
Unhealthy eating habits, physical exercise and macronutrient intakes are predictors of anthropometric indicators in the Women's Health Trial: Feasibility Study in Minority Populations
}

\author{
Alok Bhargava $^{1 *}$ and Joanne F. Guthrie ${ }^{2}$ \\ ${ }^{1}$ Department of Economics, University of Houston, Houston, TX 77204-5019, USA \\ ${ }^{2}$ Economic Research Service, US Department of Agriculture, 1800 M Street NW, Washington, DC 20036, USA
}

(Received 1 October 2001 - Revised 26 March 2002 - Accepted 17 August 2002)

\begin{abstract}
The increasing prevalence of obesity in the USA, especially among minority populations, is a serious public health concern. This present study analysed repeated measurements at baseline and at 6 and 12 months on 351 women in the control group and 575 women in the intervention group of the Women's Health Trial: Feasibility Study in Minority Populations. Dynamic random effects models were estimated using the three repeated observations to explain the effects of energy and macronutrient intakes, physical exercise, unhealthy eating habits and socio-economic characteristics on the subjects' body weights and waist and hip circumferences. In both the control and intervention groups, physical exercise was negatively associated with body weight and with waist and hip circumferences, while an index of unhealthy eating habits was positively associated $(P<0.05)$. The proportion of energy derived from carbohydrate and from saturated and monounsaturated fat were often significant predictors of body weight and of waist and hip circumferences in the two groups. The results indicated that nutrition education programmes for improving eating habits and increasing physical exercise can reduce obesity prevalence in the USA.
\end{abstract}

Dietary fat: Physical exercise: Unhealthy eating: Socio-economic factors: Random effects

The rising prevalence of obesity in the USA has spurred serious public health concerns. Medical conditions associated with obesity such as hypertension, diabetes and cardiovascular diseases are becoming increasingly costly to society (Frazao, 1999). Adults, especially from less educated populations, are susceptible to obesity. While energy imbalance is generally agreed to be a cause of weight gain, the specific role of dietary fat in promoting obesity has received some attention in the literature (Bray \& Popkin, 1998; Willett, 1998a; Rolls et al. 1999). Clinical studies have indicated the imprecise nature of the regulation of the fat balance in human subjects, especially among less active individuals (Flatt, 1987; Schutz et al. 1989; Shepard et al. 2001). Moreover, researchers have argued that the intakes of saturated, monounsaturated and polyunsaturated fats may differentially affect adiposity (Doucet et al. 1998). Analyses of longitudinal data from observational studies can afford insights into the likely effects of dietary factors on body weight and on waist and hip circumferences that have been used to predict clinical outcomes (Larsson et al. 1984; Jones et al. 1986; Rexrode et al. 1999).

In the present paper, we explore these issues by developing comprehensive longitudinal models for body weight and for waist and hip circumferences using the data from the Women's Health Trial: Feasibility Study in Minority Populations (WHTFSMP; Bowen et al. 1996). Since the subjects in the intervention group of WHTFSMP were counselled to reduce fat intakes, their dietary patterns were likely to exhibit greater variation than those in the control group. Moreover, the subjects' physical exercise patterns and measures of unhealthy eating habits and preferences were likely to reflect the difficulties in making dietary changes. These variables can be included in the models for anthropometric indicators to provide insights into the factors determining the success of dietary interventions.

An important issue for consideration is that the models postulated for anthropometric indicators are likely to influence the interpretation of the empirical results. Willett $(1998 b)$, for example, suggested the use of current energy intake as an explanatory variable in models for disease status. At a given point in time, however, subjects' energy requirements are a function of their body weights and activity levels (Food and Agricultural Organization/ World Health Organization/United Nations University, 1985; James \& Schofield, 1990; Bhargava \& Reeds, 1995). Ideally, investigators should include a measure of 
energy imbalance in models for anthropometric indicators (Prentice, 1995). This is generally unfeasible in large studies because of the large cost. Instead, we used a statistical framework that allowed possible bi-directionality in the relationship between body weight and the current energy intake. Moreover, it was possible to discriminate between the models where the intakes of carbohydrate, saturated, monounsaturated and polyunsaturated fats and the current energy intake were included as explanatory variables and where the dietary intakes were expressed as dietary intake:energy intake.

\section{Methods}

\section{Subjects}

The WHTFSMP was a multi-centre randomized trial, conducted in 1991-5 and sponsored by the National Cancer Institute, involving 2208 women in Atlanta, GA, Birmingham, AL and Miami, FL, USA, with a goal of reducing energy intakes from fat to approximately $20 \%$ in the intervention group (Bowen et al. 1996). The participants (28\% black, $16 \%$ Hispanic and $54 \%$ white) were postmenopausal women in the age group 50-79 years; 40 and $60 \%$ of the subjects were randomly assigned to the control and intervention groups respectively. Because the WHTFSMP was funded for a fixed period (Bowen et al. 1996), complete results at the baseline, 6 and 12 months on the variables used in the analysis were available for 351 women in the control group and for 575 women in the intervention group.

\section{Experimental methods}

The primary goals of the WHTFSMP were to reduce fat intakes, especially of saturated fat, and to increase the consumption of fruits, grain products and vegetables. The women in the intervention group, led by a nutritionist, met once per week in groups of eight to fifteen for the first 6 weeks, bi-weekly for the next 6 weeks and once per month thereafter for an additional 9 months. Dietary intakes at the baseline, 6 and 12 months were measured by a food-frequency questionnaire developed especially for the present study and using $4 \mathrm{~d}$ food records (Bowen et al. 1996; Kristal et al. 1997; Coates et al. 1999). However, to reduce costs, $50 \%$ of the women were randomly selected at baseline and only their $4 \mathrm{~d}$ food records were processed.

\section{The analysis of anthropometric indicators used the nutrient intakes calculated from the food-frequency questionnaire}

Each subject's age, marital status and reproductive history were recorded in the questionnaire. Education levels were coded into four categories that increased with the years of education; similarly, household incomes were coded into three groups. The subject's patterns of 'mild' and 'strenuous' physical exercise for at least $30 \mathrm{~min}$ were investigated on a scale of $1-5$ (1, never; 5 , everyday). The subjects answered, on a scale of $1-4$ (1, never; 4, very often), eight questions regarding their food cravings and preferences: (1) if they liked tasty food; (2) had craving for rich foods; (3) liked healthy foods; (4) ate more than they should; (5) whether the food consumed was satisfying; (6) felt uncomfortable with rich foods; (7) felt deprived in the absence of rich foods; (8) disliked the taste of fat. The scores on 'eating healthy foods', 'felt uncomfortable with rich foods' and 'disliked the taste of fat' were recoded so that higher scores implied less healthy eating preferences. The scores on the eight questions were subsequently summed to produce an index of 'unhealthy eating' that ranged from 8-32.

Each subject's height, body weight and waist and hip circumferences were measured at baseline and at 6 and 12 months. Height was measured with a stadiometer by rounding off to the nearest 0.5 inches; weight was measured to the nearest pound using a calibrated balanced beam scale. Using a fibreglass tape, waist circumference was measured at the smallest horizontal circumference between the ribs and the iliac crest. Hip circumference was measured at the maximum extension of the buttocks. For the analysis, body-weight measurements were converted to $\mathrm{kg}$ and height and waist and hip circumferences were expressed in $\mathrm{m}$.

\section{Analytical framework and the models for weight and waist and hip circumferences}

The body weight of an individual responds gradually to nutrient intakes and lifestyle changes; weight in the previous time period is therefore an important predictor of the current weight. While reductions in energy intakes can induce weight loss over time, the relationship between nutrient intakes and weight is likely to be smooth in most applications. Similarly, waist and hip circumferences change slowly over time and are influenced by the history of energy imbalance, physical exercise and the previous measurements. Because of the emphasis in the WHTFSMP on fat intakes, we postulated a dynamic random effects model (model 1) for the body weight of $n$ subjects using three repeated observations $(i=1,2, \ldots, n ; t=2,3)$ :

$$
\begin{aligned}
\ln (\mathrm{WT})_{\mathrm{it}}= & \mathrm{a}_{0}+\mathrm{a}_{1}(\text { black })_{\mathrm{i}}+\mathrm{a}_{2}(\text { white })_{\mathrm{i}} \\
& +\mathrm{a}_{3}(\text { education })_{\mathrm{i}}+\mathrm{a}_{4}(\text { income })_{\mathrm{i}} \\
& +\mathrm{a}_{5} \ln (\text { unhealthy eating })_{\mathrm{i}} \\
& +\mathrm{a}_{6}(\text { physical exercise })_{\mathrm{i}}+\mathrm{a}_{7} \ln (\text { height })_{\mathrm{i}} \\
& +\mathrm{a}_{8} \ln (\text { carbohydrate })_{\mathrm{it}} \\
& +\mathrm{a}_{9} \ln (\text { saturated fat })_{\mathrm{it}} \\
& +\mathrm{a}_{10} \ln (\text { monounsaturated fat })_{\mathrm{it}} \\
& +\mathrm{a}_{11} \ln (\text { polyunsaturated fat })_{\mathrm{it}} \\
& +\mathrm{a}_{12} \ln (\text { energy intake })_{\mathrm{it}}+\mathrm{a}_{13} \ln (\mathrm{WT})_{\mathrm{it}-1} \\
& +\mathrm{u}_{1 \mathrm{it}},
\end{aligned}
$$


where WT is body weight and ln is the natural logarithm. Each subject's body weight, index of unhealthy eating, carbohydrate and energy intake and the intakes of saturated, monounsaturated and polyunsaturated fats were transformed into natural logarithms, partly to reduce heteroscedasticity (Nelson et al. 1989). The coefficients of the variables expressed in logarithms were thus the 'elasticities' (a term used in economics literature for the $\%$ change in the dependent variable resulting from a $1 \%$ change in the independent variables). The model for body weight contained previous measurement of weight as an explanatory variable with coefficient $a_{13}$. The $u_{1 i t}$ were random error terms that can be decomposed in a random effects fashion as:

$$
\mathrm{u}_{1 \mathrm{it}}=\delta_{\mathrm{i}}+\mathrm{v}_{1 \mathrm{it}},
$$

where $\delta_{i}$ were subject specific random effects that were assumed to be normally distributed with zero mean and a constant variance and $\mathrm{v}_{1 \text { it }}$ were normally distributed error terms with zero mean and constant variance (Laird \& Ware, 1982).

Further, we developed a model (model 2) where the dietary intakes were expressed dietary intake:current energy intake. Since $\ln$ (carbohydrate:energy) can be written as $\ln$ (carbohydrate) $-\ln$ (energy), model 2 was a special case of model 1 with the restrictions on the coefficients in model 1 that:

$$
\mathrm{a}_{8}+\mathrm{a}_{9}+\mathrm{a}_{10}+\mathrm{a}_{11}+\mathrm{a}_{12}=0
$$

These restrictions were tested using a likelihood ratio test statistic that was distributed, for large $n$, as a $\chi^{2}$ variable with $1 \mathrm{df}$. Similar models were estimated for each subject's waist and hip circumferences. Note that while pooling the data for the control and intervention groups, an indicator variable for the subjects' group was included in models 1 and 2. Because of the nutrition education programme for the intervention group, it was of interest to test whether the model parameters in the two groups were constant. The null hypotheses of parameter constancy for the control and intervention groups were rejected in all the models and hence the empirical results are presented separately for the two groups.

It was also useful to estimate 'static' random effects models for the changes in weight between the baseline to 6 months and from 6 to 12 months (i.e. without including the previous weight change as an explanatory variable; Sheppard et al. 1991). The subjects' characteristics that were constant during the observation period (race, education, income, unhealthy eating, physical exercise and height) were omitted in explaining the weight changes. Thus, model 3 was developed for the two observations on weight changes that were explained by the changes in the intakes of carbohydrate, saturated, monounsaturated and polyunsaturated fats and energy. Another model (model 4) was estimated for weight changes with the explanatory variables expressed as the changes in the proportions of energy derived from carbohydrate and saturated, monounsaturated and polyunsaturated fats. Last, model 5 was specified for weight changes (time $(\mathrm{t}-1)-$ time $\mathrm{t})$ explained by the levels of the proportions of energy derived from carbohydrate and saturated, monounsaturated and polyunsaturated fats (at time $\mathrm{t}$ ).

\section{Statistical analysis}

For assessing the changes between the baseline and 6- and 12 -month periods in the control and intervention groups, paired $t$ tests were used to test the null hypotheses that there were no differences between the means of weight, waist and hip circumferences, energy and nutrient intakes and the energy derived from carbohydrate and saturated, monounsaturated and polyunsaturated fats. The software package SPSS (1999; SPSS Inc., Chicago, IL, USA) was used to compute the descriptive and $t$ statistics.

Since there were only three repeated time observations on the subjects, the statistical estimations of models 1-5 were based on the assumptions that the number of women $(n)$ was large, but the number of time periods was fixed. Thus, initial observations on the dependent variables (e.g. $\mathrm{WT}_{\mathrm{i} 1}$ in model 1, see p. 720) were treated as correlated with the errors (Bhargava \& Sargan, 1983). The errors (e.g. $\mathrm{u}_{1 \mathrm{it}}$ ) in the models were assumed independent across subjects, but correlated over time with a positive definite variance-covariance matrix. Details of the maximum likelihood estimation methods for models 1 and 2 are presented by Bhargava \& Sargan (1983). The static random effects models (models 3-5) were estimated using a Generalised Least Squares estimator computed in a stepwise fashion (Bhargava, 1991).

\section{Results}

\section{Descriptive statistics and tests}

The sample mean values and standard deviations of the variables used in the analysis for 351 subjects in the control group and 575 subjects in the intervention group with complete information are presented in Table 1. The sample mean values of background variables such as race, education and income and the index of unhealthy eating and exercise patterns were similar in the control and intervention groups. For the control group, there were significant $(P<0.05)$ changes between the baseline and 12 months in all variables except weight and waist circumference; changes between the 6- and 12-month periods were substantially smaller. The mean energy intakes declined from 7223 to $6243 \mathrm{~kJ}$, constituting a $16 \%$ reduction. There was a decline of approximately $20 \%$ in the intake of saturated, monounsaturated and polyunsaturated fats. The intakes of saturated fat $(\mathrm{g})$ at percentiles $10,30,50$, 70 and 90 were $10 \cdot 1$ v. $7.9,17 \cdot 0$ v. $13 \cdot 2,22.6$ v. 17.9, 30.1 v. 23.9 and $44 \cdot 1$ v. 37.3 at baseline and 12 months respectively. Even in the absence of counselling, the subjects reduced their saturated fat intakes, presumably due to the minimal information (Unites States Department of Agriculture/Department of Health and Human Services, 1990) that they received through participating as controls.

The changes in the intervention group between the baseline and 12 months were statistically significant for all variables $(P<0.05)$. The reduction in energy intake was approximately $27 \%$. The corresponding changes in 
Table 1. Selected variables for 351 women in the control group and 575 women in the intervention group at baseline, 6 months and 12 months $\ddagger \S$ (Mean values and standard deviations)

\begin{tabular}{|c|c|c|c|c|c|c|c|c|c|c|c|c|}
\hline & \multicolumn{6}{|c|}{ Control group ( $n$ 351) } & \multicolumn{6}{|c|}{ Intervention group ( $n$ 575) } \\
\hline & \multicolumn{2}{|c|}{ Baseline } & \multicolumn{2}{|c|}{6 months } & \multicolumn{2}{|c|}{12 months } & \multicolumn{2}{|c|}{ Baseline } & \multicolumn{2}{|c|}{6 months } & \multicolumn{2}{|c|}{12 months $\dagger$} \\
\hline & Mean & SD & Mean & SD & Mean & SD & Mean & SD & Mean & SD & Mean & SD \\
\hline Age (years) & 59.9 & $6 \cdot 6$ & & & & & $60 \cdot 1$ & $6 \cdot 6$ & & & & \\
\hline Black $(0-1) \|$ & 0.38 & 0.49 & & & & & 0.34 & 0.48 & & & & \\
\hline White $(0-1) \|$ & 0.56 & 0.50 & & & & & 0.57 & 0.50 & & & & \\
\hline Education $(1-4) \|$ & $2 \cdot 91$ & 1.00 & & & & & 2.98 & 1.00 & & & & \\
\hline Income $(1-3) \|$ & 1.96 & 0.48 & & & & & 1.98 & 0.50 & & & & \\
\hline Unhealthy eating $(8-32) \|$ & $21 \cdot 1$ & $2 \cdot 84$ & & & & & $21 \cdot 3$ & 2.91 & & & & \\
\hline Physical exercise $(1-5) \|$ & $2 \cdot 84$ & 1.22 & & & & & $2 \cdot 86$ & 1.33 & & & & \\
\hline Height $(m)$ & 1.62 & 0.06 & & & & & 1.63 & 0.06 & & & & \\
\hline Weight (kg) & $76 \cdot 2$ & 12.5 & $76 \cdot 0$ & $12 \cdot 5$ & $75 \cdot 9$ & $12 \cdot 7$ & 76.0 & $12 \cdot 7$ & 74.0 & $12 \cdot 7$ & $73 \cdot 8^{*}$ & $12 \cdot 8$ \\
\hline Waist circumference (m) & 0.86 & 0.11 & 0.86 & 0.11 & 0.86 & 0.11 & 0.87 & 0.11 & 0.85 & $0 \cdot 11$ & $0.85^{*}$ & 0.11 \\
\hline Hip circumference (m) & 1.09 & 0.09 & 1.08 & 0.09 & $1.08^{*}$ & 0.10 & 1.09 & 0.09 & 1.07 & 0.09 & $1.07^{*}$ & 0.10 \\
\hline Energy intake (kJ) & 7223 & 3262 & 6485 & 3067 & $6243^{*}$ & 3188 & 7489 & 3736 & 5406 & 2284 & $5448^{*}$ & 2423 \\
\hline Carbohydrate (g) & 191 & $85 \cdot 6$ & 180 & 84.0 & $174^{\star}$ & 87.3 & 198 & 104 & 181 & 77.9 & $186^{*}$ & 83.0 \\
\hline Saturated fat $(\mathrm{g})$ & $25 \cdot 2$ & 14.5 & 21.6 & 13.0 & $20 \cdot 8^{\star}$ & $14 \cdot 0$ & $27 \cdot 1$ & $16 \cdot 0$ & $13 \cdot 1$ & 7.7 & $13 \cdot 0^{*}$ & 8.2 \\
\hline Monounsaturated fat $(\mathrm{g})$ & $28 \cdot 6$ & $15 \cdot 5$ & $24 \cdot 3$ & 14.0 & $22 \cdot 9^{\star}$ & $14 \cdot 3$ & $30 \cdot 3$ & $16 \cdot 7$ & 14.0 & 8.5 & $13 \cdot 8^{\star}$ & 8.6 \\
\hline Polyunsaturated fat (g) & $17 \cdot 0$ & 9.6 & 14.0 & 8.4 & $13 \cdot 3^{*}$ & 9.0 & $17 \cdot 5$ & $10 \cdot 0$ & 7.8 & $5 \cdot 3$ & $7 \cdot 6^{*}$ & 4.8 \\
\hline Carbohydrate (\% energy) & $45 \cdot 2$ & 8.0 & $47 \cdot 2$ & 8.8 & $47 \cdot 5^{\star}$ & $8 \cdot 8$ & 44.5 & $7 \cdot 7$ & 56.6 & 9.4 & $57.7^{\star}$ & 9.6 \\
\hline SFA (\% energy) & $12 \cdot \overline{8}$ & 3.0 & $12 \cdot \overline{2}$ & 3.0 & $12 \cdot 0^{*}$ & $3 \cdot 1$ & 13.3 & $2 \cdot 8$ & 8.9 & $2 \cdot 6$ & $8.7^{*}$ & 2.7 \\
\hline MUFA (\% energy) & 14.5 & $3 \cdot 0$ & $13 \cdot 8$ & 3.1 & $13 \cdot 4^{\star}$ & $3 \cdot 1$ & $15 \cdot 0$ & $2 \cdot 9$ & 9.6 & $3 \cdot 2$ & $9 \cdot 3^{*}$ & $3 \cdot 2$ \\
\hline PUFA ( $\%$ energy) & 8.7 & $2 \cdot 4$ & 8.0 & 2.5 & $7 \cdot 8^{*}$ & 2.5 & 8.8 & 2.5 & $5 \cdot 4$ & $2 \cdot 1$ & $5 \cdot 2^{*}$ & 2.2 \\
\hline
\end{tabular}

SFA, saturated fatty acid; MUFA, monounsaturated fatty acid; PUFA, polyunsaturated fatty acid.

Mean values were significantly different from baseline values for each group: ${ }^{*} P<0.05$.

Mean values for the change between baseline and 12 months were significantly different from those of the control group except for carbohydrate intake: $\dagger P<0.05$.

¥For details of subjects and procedures, see p. 720.

$\S$ Dietary intakes were based on a food-trequency questionnaire.

\| For details of scoring system, see p. 720. 
weight and waist and hip circumferences were 3,2 and 2\% respectively. While it was possible that the subjects underreported their energy intakes, the reported intakes of saturated, monounsaturated and polyunsaturated fat were reduced to $<50 \%$ of the levels at the baseline. The intakes of saturated fat at percentiles 10,30, 50, 70 and 90 were $10 \cdot 1$ v. $5 \cdot 0,17.7$ v. $8 \cdot 2,24.5$ v. $11.5,32 \cdot 2$ v. 14.9 and 46.6 v. 23.5 at baseline and 12 months respectively. The reductions in saturated fat intakes especially by women consuming high-fat diets at the baseline were impressive. There was a $23 \%$ increase in the $\%$ energy derived from carbohydrate. Overall, in comparison with the control group, the educational programme for the intervention group helped lower fat and energy intakes and promoted greater weight loss.

\section{Empirical results for body weight in the control and intervention groups}

The empirical results from estimating the models for weight of the subjects in the control and intervention groups are presented in Table 2. Model 1 included the current energy intake and the levels of carbohydrate and fat intakes. In model 2, the nutrient intakes were expressed as nutrient intakes:energy intake. Allowing for different mean values in the control and intervention groups, a likelihood ratio test rejected the null hypothesis of parameters constancy in the two groups $\left(\chi^{2} 56 \cdot 4\right.$, df $\left.14, P<0 \cdot 001\right)$. Thus, the dynamic models were estimated separately for the control and intervention groups.

For the control group, the results for models 1 and 2 showed that white women and women from better-off households were significantly lighter $(P<0 \cdot 05)$. The index of unhealthy eating was positively associated with weight, while the reported frequency of mild physical exercise was negatively associated. These results underscored the importance of behavioural factors such as craving for rich foods and physical exercise for body weight. Height was a significant predictor of weight. The estimated coefficients from models 1 and 2 were significantly $(P<0.05)$ lower than the value 2 that would have indicated a preference for combining (the logarithms of) height and weight as the BMI (Bhargava, 1994). The estimated coefficient of the current energy intake in model 1 for the control group was negative and statistically significant $(P<0.05)$. The likelihood ratio test rejected the restrictions on the coefficients of model 1 at the $5 \%$ significance level, though the null hypothesis was accepted at the $2.5 \%$ level. The estimated coefficients of models 1 and 2 were close, suggesting that the conclusions based on either formulation would be similar. The standard errors of the coefficients were slightly lower in model 2 because of the coefficient restrictions. The coefficients of monounsaturated fat were positive and significant $(P<0.05)$ in

Table 2. Maximum likelihood estimates of dynamic random effects models for the weight of women in the control and intervention groups explained by socio-economic variables and nutrient intakes†‡

(Slope coefficients with their standard errors)

\begin{tabular}{|c|c|c|c|c|c|c|c|c|}
\hline & \multicolumn{8}{|c|}{ Weight (kg) } \\
\hline & \multicolumn{4}{|c|}{ Control group ( $n$ 351) } & \multicolumn{4}{|c|}{ Intervention group ( $n$ 575) } \\
\hline & \multicolumn{2}{|c|}{ Model 1} & \multicolumn{2}{|c|}{ Model 2\| } & \multicolumn{2}{|c|}{ Model 1} & \multicolumn{2}{|c|}{ Model 2\| } \\
\hline & Coeff & SE & Coeff & SE & Coeff & SE & Coeff & SE \\
\hline Constant & $2 \cdot 100^{*}$ & 0.049 & $2 \cdot 197^{\star}$ & 0.320 & $2 \cdot 094^{*}$ & 0.190 & $2 \cdot 114^{\star}$ & 0.161 \\
\hline Black $(0-1) \emptyset$ & 0.024 & 0.017 & 0.022 & 0.011 & $0.032^{*}$ & 0.017 & $0.032^{*}$ & 0.012 \\
\hline White $(0-1)$ & $-0.035^{\star}$ & 0.017 & $-0.038^{\star}$ & 0.012 & $-0.028^{\star}$ & 0.014 & $-0.028^{\star}$ & 0.011 \\
\hline Education $(1-4) \emptyset$ & 0.0004 & 0.003 & 0.0008 & 0.002 & $-0.012^{*}$ & 0.003 & $-0.012^{*}$ & 0.003 \\
\hline Income $(1-3)$ & -0.008 & 0.005 & $-0.010^{\star}$ & 0.005 & -0.006 & 0.009 & -0.006 & 0.007 \\
\hline Unhealthy eating (8-32)§ף & $0 \cdot 126^{\star}$ & 0.017 & $0.133^{*}$ & 0.041 & $0 \cdot 140^{\star}$ & 0.028 & $0 \cdot 145^{\star}$ & 0.021 \\
\hline Physical exercise $(1-5) \emptyset$ & $-0.007^{\star}$ & 0.003 & $-0.007^{\star}$ & 0.002 & $-0.009^{\star}$ & 0.003 & $-0.009^{\star}$ & 0.002 \\
\hline Height $(m) \S$ & $0.776^{\star}$ & 0.130 & $0.804^{*}$ & 0.144 & $1.061^{*}$ & 0.133 & $1.074^{\star}$ & 0.122 \\
\hline Energy intake (kJ) & $-0.087^{\star}$ & 0.021 & - & & -0.028 & 0.027 & - & \\
\hline Carbohydrate $(\mathrm{g}) \S$ & $0.033^{*}$ & 0.013 & - & & 0.010 & 0.018 & - & \\
\hline Saturated fat $(\mathrm{g}) \S$ & 0.018 & 0.013 & - & & -0.018 & 0.014 & - & \\
\hline Polyunsaturated fat $(\mathrm{g}) \S$ & 0.0006 & 0.009 & - & & 0.007 & 0.009 & - & \\
\hline Carbohydrate:energy§ & - & & $0.032^{*}$ & 0.016 & - & & 0.010 & 0.013 \\
\hline Saturated fat:energy§ & - & & 0.019 & 0.016 & - & & -0.018 & 0.012 \\
\hline Monounsaturated fat:energy§ & - & & $0.051^{*}$ & 0.019 & - & & $0.034^{*}$ & 0.017 \\
\hline Polyunsaturated fat:energy§ & - & & -0.002 & 0.010 & - & & 0.006 & 0.009 \\
\hline Lagged dependent variable§ & $0.411^{*}$ & 0.029 & $0.401^{*}$ & 0.088 & $0.332^{*}$ & 0.045 & $0.329^{\star}$ & 0.047 \\
\hline Between:within variance & $8 \cdot 245^{\star}$ & $1 \cdot 260$ & $8 \cdot 648^{\star}$ & 3.012 & $9 \cdot 337^{\star}$ & 1.686 & $9 \cdot 399^{\star}$ & 1.623 \\
\hline Within variance & 0.0009 & & 0.0009 & & 0.0011 & & 0.0011 & \\
\hline
\end{tabular}

Coeff, coefficient.

${ }^{\star} P<0.05$.

†For details of subjects and procedures, see p. 720 .

$\ddagger$ Dietary intakes were based on a food-frequency questionnaire.

II The intakes in model 2 were expressed intake:energy intake.

$\S$ Transformed into natural logarithms.

If For details of scoring system, see p. 720 
models 1 and 2. This was not true for saturated and polyunsaturated fat intakes where the estimated coefficients in both models were not statistically different from zero.

The estimated coefficients of the lagged dependent variables were approximately 0.40 for models 1 and 2 and were significant $(P<0.05)$, thereby underscoring the need for taking into account the history of subject's' body weight when investigating the effects of nutrient intakes. The between:within variance ratios were large and significant $(P<0.05)$, suggesting that the between-subject differences in the sample were partially accounted for by the background variables, index of unhealthy eating, physical exercise patterns and nutrient intakes. Since weight responds gradually to small imbalances in energy intake and expenditure, it was reasonable to expect that the explanatory variables measured at three time points would not account for the entire history of energy imbalances.

The results shown in Table 2 for women in the intervention group were broadly similar to the results for the control group. Black women were heavier and white women were lighter than Hispanic women $(P<0.05)$. The coefficient of education was statistically significant $(P<0.05)$ in models 1 and 2, suggesting that highly educated women benefited more from the counselling. Since the coefficient of education was not statistically significant in the control group, awareness of the counselling programme by itself was insufficient to induce behavioural changes leading to weight loss among the more educated women.

The coefficients of the index of unhealthy eating and physical exercise patterns in models 1 and 2 were similar for the control and intervention groups and were statistically significant $(P<0 \cdot 05)$. However, only the intakes of monounsaturated fat were positively associated with weight in the intervention group. Coefficient of weight in the previous period was slightly lower for the intervention group and the estimates of the within-subject variance were slightly higher. The coefficient of energy intake in model 1 was not statistically different from zero. Last, the subjects' age and age-squared were significant predictors of weight; the parameter estimates reported in Table 2 were not noticeably affected by inclusion of the age variables in the models.

\section{Empirical results for waist and hip circumferences in the control and intervention groups}

The results from estimating models 1 and 2 for waist circumference of the women in the control and intervention groups are presented in Table 3. In the control group, household incomes and physical exercise patterns were negatively associated with waist circumference whereas the index of unhealthy eating habits was positively

Table 3. Maximum likelihood estimates of dynamic random effects models for the waist circumference of women in the control and intervention groups explained by socio-economic variables and nutrient intakes†‡

(Slope coefficients with their standard errors)

\begin{tabular}{|c|c|c|c|c|c|c|c|c|}
\hline & \multicolumn{8}{|c|}{ Waist circumference $(\mathrm{m}) \S$} \\
\hline & \multicolumn{4}{|c|}{ Control group ( $n$ 351) } & \multicolumn{4}{|c|}{ Intervention group ( $n$ 575) } \\
\hline & Coeff & SE & Coeff & SE & Coeff & SE & Coeff & SE \\
\hline Constant & -0.136 & 0.173 & 0.054 & 0.143 & $-0.514^{\star}$ & 0.103 & $-0.517^{\star}$ & 0.132 \\
\hline White $(0-1)$ & 0.009 & 0.017 & -0.001 & 0.017 & -0.023 & 0.015 & -0.023 & 0.015 \\
\hline Education $(1-4) \emptyset$ & -0.004 & 0.004 & -0.004 & 0.004 & $-0.008^{*}$ & 0.004 & $-0.008^{*}$ & 0.004 \\
\hline Income $(1-3) \emptyset$ & $-0.016^{\star}$ & 0.008 & $-0.018^{*}$ & 0.008 & -0.014 & 0.008 & -0.014 & 0.008 \\
\hline Unhealthy eating (8-32)§ & 0.051 & 0.031 & $0 \cdot 060^{\star}$ & 0.028 & $0 \cdot 114^{\star}$ & 0.029 & $0.114^{*}$ & 0.027 \\
\hline Physical exercise $(1-5) \emptyset$ & $-0.007^{\star}$ & 0.003 & $-0.007^{\star}$ & 0.003 & $-0.010^{\star}$ & 0.002 & $-0.010^{\star}$ & 0.003 \\
\hline Height $(\mathrm{m}) \S$ & 0.170 & 0.101 & $0.192^{*}$ & 0.101 & $0.237^{\star}$ & $0 \cdot 110$ & $0.237^{*}$ & 0.109 \\
\hline Energy intake $(\mathrm{kJ}) \S$ & $-0.090^{\star}$ & 0.040 & - & & 0.003 & 0.019 & - & \\
\hline Carbohydrate (g)§ & $0.048^{*}$ & 0.023 & - & & -0.007 & 0.015 & - & \\
\hline Saturated fat $(\mathrm{g}) \S$ & $0.039^{*}$ & 0.020 & - & & -0.024 & 0.014 & - & \\
\hline Polyunsaturated fat $(\mathrm{g}) \S$ & 0.012 & 0.013 & - & & -0.011 & 0.010 & - & \\
\hline Carbohydrate:energy§ & - & & $0.047^{*}$ & 0.021 & - & & -0.007 & 0.020 \\
\hline Saturated fat:energy§ & - & & $0.041^{\star}$ & 0.017 & - & & $-0.025^{\star}$ & 0.011 \\
\hline Monounsaturated fat:energy§ & - & & 0.009 & $0 \cdot 012$ & - & & $0.040^{\star}$ & 0.008 \\
\hline Polyunsaturated fat:energy§ & - & & 0.010 & 0.011 & - & & -0.011 & 0.008 \\
\hline Lagged dependent variable§ & $0.453^{\star}$ & 0.103 & $0.431^{*}$ & 0.099 & $0 \cdot 237^{\star}$ & 0.056 & $0 \cdot 235^{\star}$ & 0.056 \\
\hline Between:within variance & $1.986^{\star}$ & 0.979 & $2 \cdot 210^{\star}$ & 0.988 & $4 \cdot 969^{*}$ & 1.008 & $5 \cdot 006^{\star}$ & 1.007 \\
\hline Within variance & $0 \cdot 0018$ & & 0.0018 & & 0.0016 & & 0.0016 & \\
\hline
\end{tabular}

Coeff, coefficient.

${ }^{*} P<0.05$.

†For details of subjects and procedures, see p. 720 .

$\ddagger$ Dietary intakes were based on a food-frequency questionnaire.

$\S$ Transformed into natural logarithms.

\| The intakes in model 2 were expressed at intake:energy intake.

If For details of scoring system, see p. 720. 
associated $(P<0.05)$. The estimated coefficient of height was small and statistically significant $(P<0.05)$ only in model 2. Energy intake in model 1 was estimated with a negative sign that was significant. The intakes of carbohydrate and saturated fat were significant $(P<0.05)$ and positively associated with waist circumference in both model 1 and 2. The coefficients of the lagged dependent variables for waist circumference were close to those for body weight reported in Table 2 .

In the intervention group, education was negatively associated with waist circumference. The index of unhealthy eating habits and physical exercise patterns were significantly associated with waist circumference of the women in the intervention group. Moreover, while the carbohydrate and saturated fat intakes were not significant predictors, the intake of monounsaturated fat was a significant predictor. Some of the differences between the control and intervention groups were likely to be due to the relative changes in the intakes of saturated, monounsaturated and polyunsaturated fats. This issue will be further addressed later. The coefficients of the lagged dependent variables were lower, whereas the between:within variance ratios were higher in the intervention group.

Table 4 presents the results for the hip circumferences of women in the control and intervention groups. Again, the index of unhealthy eating habits and physical exercise patterns were significant $(P<0.05)$ predictors for both groups. The magnitude of these coefficients was similar to the results for weight and waist circumference in Tables 2 and 3 respectively. Height was positively associated with hip circumference. Energy intakes were estimated with negative signs for both groups and were statistically significant. The intake of monounsaturated fat was a significant predictor of hip circumference in the control group; the fat intakes were not significant predictors in the intervention group. The coefficients of the lagged dependent variables were smaller and the between:within variance ratios were larger for the control group.

\section{Empirical results for weight changes in the control and intervention groups}

Table 5 presents the results for the models for weight changes in the control and intervention groups. In model 3 , the explanatory variables were the corresponding changes in the intakes of carbohydrate and saturated, monounsaturated and polyunsaturated fats and energy. In model 4, the explanatory variables were expressed as changes in the proportions of energy derived from carbohydrate and saturated, monounsaturated and polyunsaturated fats. The proportions of energy from these macronutrients in levels were the explanatory variables in model 5.

In the results from model 3 , the coefficients of energy

Table 4. Maximum likelihood estimates of dynamic random effects models for the hip circumference of women in the control and intervention groups explained by socio-economic variables and nutrient intakes†‡

(Slope coefficients with their standard errors)

\begin{tabular}{|c|c|c|c|c|c|c|c|c|}
\hline & \multicolumn{8}{|c|}{ Hip circumference $(\mathrm{m}) \S$} \\
\hline & \multicolumn{4}{|c|}{ Control group (n 351) } & \multicolumn{4}{|c|}{ Intervention group ( $n$ 575) } \\
\hline & \multicolumn{2}{|c|}{ Model 1} & \multicolumn{2}{|c|}{ Model 2\| } & \multicolumn{2}{|c|}{ Model 1} & \multicolumn{2}{|c|}{ Model 2\| } \\
\hline & Coeff & SE & Coeff & SE & Coeff & SE & Coeff & SE \\
\hline Constant & -0.254 & $0 \cdot 135$ & -0.213 & $0 \cdot 145$ & $-0.264^{\star}$ & 0.062 & $-0.249^{\star}$ & 0.075 \\
\hline White $(0-1) \emptyset$ & -0.021 & 0.019 & -0.023 & 0.019 & -0.008 & 0.009 & -0.008 & 0.009 \\
\hline Education $(1-4)$ I & 0.003 & 0.004 & 0.004 & 0.004 & $-0.006^{\star}$ & 0.003 & $-0.006^{\star}$ & 0.003 \\
\hline Income $(1-3) \emptyset$ & -0.009 & 0.008 & -0.010 & 0.009 & -0.004 & 0.005 & -0.004 & 0.005 \\
\hline Unhealthy eating (8-32)§ף & $0.090^{\star}$ & 0.031 & $0.094^{\star}$ & 0.032 & $0 \cdot 070^{\star}$ & 0.019 & $0.071^{\star}$ & 0.018 \\
\hline Physical exercise $(1-5) \emptyset$ & $-0.008^{*}$ & 0.003 & $-0.008^{\star}$ & 0.003 & $-0.005^{\star}$ & 0.002 & $-0.005^{\star}$ & 0.002 \\
\hline Height $(m) \S$ & $0 \cdot 292^{*}$ & $0 \cdot 107$ & $0.300^{*}$ & $0 \cdot 104$ & $0.331^{*}$ & 0.074 & $0.334^{*}$ & 0.072 \\
\hline Energy intake $(\mathrm{kJ}) \S$ & -0.024 & 0.026 & - & & $-0.013^{\star}$ & 0.002 & - & \\
\hline Carbohydrate $(\mathrm{g}) \S$ & 0.012 & $0 \cdot 015$ & - & & 0.008 & 0.005 & - & \\
\hline Saturated fat $(\mathrm{g})$ & -0.004 & 0.015 & - & & -0.0002 & 0.011 & - & \\
\hline Polyunsaturated fat $(\mathrm{g}) \S$ & -0.010 & 0.010 & - & & -0.003 & 0.007 & - & \\
\hline Carbohydrate:energy§ & - & & 0.011 & 0.018 & - & & 0.007 & 0.013 \\
\hline Saturated fat:energy§ & - & & -0.003 & 0.015 & - & & 0.0004 & 0.012 \\
\hline Monounsaturated fat:energy§ & - & & 0.037 & 0.019 & - & & $0 \cdot 011$ & 0.013 \\
\hline Polyunsaturated fat:energy§ & - & & -0.012 & $0 \cdot 010$ & - & & -0.003 & 0.008 \\
\hline Lagged dependent variable§ & 0.069 & 0.078 & 0.067 & 0.078 & $0 \cdot 279^{*}$ & 0.053 & $0 \cdot 283^{*}$ & 0.054 \\
\hline Between:within variance & $6 \cdot 520^{\star}$ & 1.600 & $6 \cdot 598^{*}$ & 1.604 & $3.557^{*}$ & 0.719 & $3.482^{*}$ & 0.715 \\
\hline Within variance & $0 \cdot 0008$ & & $0 \cdot 0008$ & & 0.0009 & & 0.0009 & \\
\hline
\end{tabular}

Coeff, coefficient.

${ }^{\star} P<0.05$.

† For details of subjects and procedures, see p. 720 .

‡Dietary intakes based on a food-frequency questionnaire.

$\S$ Transformed into natural logarithms.

\| The intakes in model 2 were expressed as intake:energy intake.

If For details of scoring system, see p. 720 
Table 5. Efficient estimates of three versions of static random effects models for weight changes of the women in the control and intervention groups explained by the changes in carbohydrate, saturated, monounsaturated and polyunsaturated fat and by transformations of the explanatory variables $\dagger \neq \S$

(Slope coefficients and standard errors)

\begin{tabular}{|c|c|c|c|c|c|c|c|c|c|c|c|c|}
\hline & \multicolumn{12}{|c|}{ Weight change (kg) } \\
\hline & \multicolumn{6}{|c|}{ Control group ( $n$ 351) } & \multicolumn{6}{|c|}{ Intervention group ( $n$ 575) } \\
\hline & \multicolumn{2}{|c|}{ Model 3\| } & \multicolumn{2}{|c|}{ Model 4ף } & \multicolumn{2}{|c|}{ Model 5†† } & \multicolumn{2}{|c|}{ Model 3\| } & \multicolumn{2}{|c|}{ Model 4ף } & \multicolumn{2}{|c|}{ Model 5†† } \\
\hline & Coeff & SE & Coeff & SE & Coeff & SE & Coeff & SE & Coeff & SE & Coeff & SE \\
\hline Constant & -0.001 & 0.001 & -0.001 & 0.001 & $0.172^{*}$ & 0.057 & $-0.006^{*}$ & 0.001 & $-0.006^{*}$ & 0.001 & $0 \cdot 179^{*}$ & 0.044 \\
\hline Change in carbohydrate $(\mathrm{g})$ & $0.042^{*}$ & 0.014 & - & & - & & 0.015 & 0.011 & - & & - & \\
\hline Change in saturated fat (g) & 0.015 & 0.011 & - & & - & & 0.008 & 0.009 & - & & - & \\
\hline Change in monounsaturated fat $(\mathrm{g})$ & $0.052^{*}$ & 0.014 & - & & - & & 0.012 & 0.011 & - & & - & \\
\hline Change in polyunsaturated fat $(\mathrm{g})$ & -0.003 & 0.007 & - & & - & & $0.022^{*}$ & 0.005 & - & & - & \\
\hline Change in energy $(\mathrm{kJ})$ & $0.013^{*}$ & 0.024 & - & & - & & $-0.054^{*}$ & 0.018 & - & & - & \\
\hline Change in carbohydrate (\% energy) & - & & $0.042^{*}$ & 0.014 & & & - & & 0.016 & 0.011 & & \\
\hline Change in saturated fat (\% energy) & - & & 0.016 & 0.011 & & & - & & 0.001 & 0.009 & & \\
\hline Change in monounsaturated fat (\% energy) & - & & $0.052^{*}$ & 0.014 & & & - & & 0.012 & 0.011 & & \\
\hline Change in polyunsaturated fat (\% energy) & - & & -0.004 & 0.007 & & & - & & $0.022^{*}$ & 0.007 & & \\
\hline Carbohydrate (\% energy) & - & & - & & 0.018 & 0.011 & - & & - & & 0.018 & 0.010 \\
\hline Saturated fat (\% energy) & - & & - & & 0.005 & 0.009 & - & & - & & 0.006 & 0.009 \\
\hline Monounsaturated fat (\% energy) & - & & - & & $0.024^{*}$ & 0.012 & - & & - & & 0.010 & 0.011 \\
\hline Polyunsaturated fat (\% energy) & - & & - & & 0.003 & 0.006 & - & & - & & $0.016^{\star}$ & 0.006 \\
\hline
\end{tabular}

Coeff, coefficient

${ }^{\dagger} P<0.05$.

The dependent variable and all explanatory variables were transformed into natural logarithms.

$\S$ Dietary intakes were based on a food-frequency questionnaire.

Model 3 explained the changes in weight by the changes in intakes.

9 Model 4 explained changes in weight by the changes in the \% energy derived from the intakes.

t† Model 5 explained the changes in weight by the level of $\%$ energy derived from the intakes. 
intakes were estimated with negative signs and were statistically significant $(P<0.05)$ for both the control and intervention groups. These negative estimates were broadly similar to the estimated coefficients of energy intakes in the model for weight in Table 2. Thus, the results again suggested that weight changes might be better explained by the changes in the proportions of energy derived from carbohydrate and saturated, monounsaturated and polyunsaturated fats. The results for model 4 in Table 5 were close to those obtained from estimating model 3. Moreover, in the control group, the \% energy derived from carbohydrate and monounsaturated fat was positively associated with weight changes. By contrast, the \% energy derived from polyunsaturated fat was positively associated in the intervention group.

Further, the results from model 5 with the explanatory variables in levels showed positive associations between energy derived from monounsaturated fat and weight changes in the control group. By contrast, a greater proportion of energy from polyunsaturated fat was associated with weight gain in the intervention group. A possible explanation of these findings was that, although some women in the intervention group had lowered their saturated fat intakes due to the nutrition education programme, they might have subsequently increased the intake of polyunsaturated fat thereby increasing the overall energy intake (Guthrie et al. 1999). Overall, while the results in Tables 2 and 5 showed significant effects of macronutrient intakes on body weight and weight changes, the results were ambiguous with regard to the evidence on the possible link between the subjects' fat intakes and body weights. Moreover, the inclusion of protein intakes in models 1 and 2 led to very similar results and indicated a preference of the conversion of dietary intakes:energy intake.

\section{Discussion}

This present study analysed the effects of the dietary intervention in the WHTFSMP. The proximate determinants of weight and waist and hip circumferences in the control and intervention groups were modelled using repeated measurements at baseline, 6 and 12 months. The dietary intakes calculated from the food-frequency questionnaire showed significant $(P<0.05)$ reductions between baseline and 12 months in the intakes of energy and saturated, monounsaturated and polyunsaturated fats for both groups; the changes between the 6- and 12-month periods were smaller. The reductions in intakes between baseline and 12 months were greater for the intervention group.

Between baseline and 12 months, the mean body weight and waist and hip circumferences of women in the intervention group were reduced by 3,2 and $2 \%$ respectively. By contrast, there was only a slight reduction in hip circumference of women in the control group. The comprehensive longitudinal data provided an opportunity to model the associations between background, lifestyle and nutritional variables and the anthropometric indicators. Separate analyses were performed for the control and intervention groups because of the differences in the model parameters for the two groups.

The results from the models for weight and waist and hip circumferences showed the importance of physical exercise and unhealthy eating habits for the anthropometric indicators; mild exercise appeared to be helpful in reducing body weight and waist and hip circumferences. These findings merit a further consideration from those designing educational programmes for dietary improvements. For example, using the question items regarding unhealthy eating habits in the WHTFSMP, investigators can identify the women who will face greater difficulties in responding to nutrition education; such women can be offered additional guidance for making dietary changes.

While the education variable was a significant predictor of anthropometric indicators in the intervention group, education was not a significant predictor in the control group. Higher education levels may have made it easier for women to understand and apply the nutrition guidance provided as part of the intervention. Given the wide prevalence of obesity among less educated women in lowincome households, special attention is necessary for devising effective education programmes for such subjects. It is essential that women receive dietary advice before they reach a stage where excess weight leads to conditions such as non-insulin-dependent diabetes mellitus.

The longitudinal data analysis also attempted to separate out the effects of intakes of energy, carbohydrate and saturated, monounsaturated and polyunsaturated fat on anthropometric indicators. For example, the \% energy derived from carbohydrate and saturated and monounsaturated fats was often a positive and significant predictor of the anthropometric indicators in the two groups. In the models for weight changes, higher $\%$ energy from monounsaturated fat was associated with weight gain in the control group. By contrast, energy derived from polyunsaturated fat was a positive predictor of weight gain in the intervention group. The empirical results did not point to a clear link between the intakes of the three types of fat and body weight; reporting biases in the intakes might have influenced some of the findings (Bingham, 1994; Buzzard et al. 1996). For reasons of small sample sizes, the random effects models were not separately estimated for the black, Hispanic and white women.

The results from observational and experimental studies can often be combined to provide useful insights into the factors affecting body weight. For example, physical exercise was an important predictor of body weight and waist and hip circumferences in the WHTFSMP data. The importance of physical exercise has been documented in experimental studies measuring fat oxidation in subjects consuming high-fat diets (Smith et al. 2000); only a few subjects were studied for a limited number of days due to the large costs. While increased physical activity decreased the (positive) fat balance in the subjects, it was unclear whether such fat imbalances would persist for long periods in physically active individuals.

Last, it is important to emphasize the guidelines encouraging the maintenance of a healthy body weight or the BMI. Because high-fat foods are energy dense, from a practical standpoint, a diet with low-energy density is likely to be moderately low in fat (United States Department of Agriculture/Department of Health and Human Services, 2000). The results from WHTFSMP indicate 
that making lifestyle changes such as improving dietary habits and increasing physical exercise can be effective in reducing weight and waist and hip circumferences. In view of the high costs of caring for chronic diseases due to over-nutrition, preventive efforts, such as nutrition education, merit greater emphasis.

\section{Acknowledgements}

This paper is dedicated to the memory of Professor Peter J. Reeds, who was a true scholar, mentor, critic and friend. The authors are greatly indebted to Dr Carolyn Clifford of the National Cancer Institute, who sadly passed away on 31 May 2001. Thanks are due to Dr Peter Basiotis, Professor Tim Cole, Dr Albert Oberman and the two referees for helpful comments. The views contained in this paper are exclusively those of the authors. This research was supported through a Cooperative Agreement between the Economic Research Service of the USA Department of Agriculture and the University of Houston.

\section{References}

Bhargava A (1991) Identification and panel data models with endogenous regressors. Review of Economic Studies 58, 129-140.

Bhargava A (1994) Modelling the health of Filipino children. Journal of the Royal Statistical Society Series A 157, 417-432.

Bhargava A \& Reeds P (1995) Requirements for what? Is the measurement of energy expenditure a sufficient estimate of energy needs? Journal of Nutrition 125, 1358-1362.

Bhargava A \& Sargan JD (1983) Estimating dynamic random effects models from panel data covering short time periods. Econometrica 51, 1635-1660.

Bingham SA (1994) The use of 24-hour urine samples and energy expenditures to validate dietary assessment. American Journal of Clinical Nutrition 59, 227S-231S.

Bowen D, Clifford CC, Coates R, Evans M, Feng Z, Fouad M, George V, Gerace T, Grizzle JE, Hall WD, Heam M, Henderson M, Kestin M, Kristal A \& Leary ET et al. (1996) The Women's Health Trial Feasibility Study in Minority Populations: Design and baseline description. Annals of Epidemiology 6, 507-519.

Bray G \& Popkin B (1998) Dietary fat intake does affect obesity! American Journal of Clinical Nutrition 68, 1157-1173.

Buzzard IM, Faucett CL, Jeffery RW, McBane L, McGovern P, Baxter JS, Shapiro AC, Blackburn GL, Chlebowski RT, Elashoff RM \& Wynder EL (1996) Monitoring dietary change in a lowfat diet intervention study: Advantages of using 24-hour dietary recalls versus food records. Journal of American Dietetic Association 96, 574-579.

Coates R, Bowen DJ, Kristal AR, Feng Z, Oberman A, Hall DW, George V, Lewis CE, Kestin M, Davis M, Evans M, Grizzle JE \& Clifford C (1999) The Women's Health Trial Feasibility Study in Minority Populations: Changes in dietary intakes. American Journal of Epidemiology 149, 1104-1112.

Doucet E, Almeras N, White MD, Despres J-P, Bouchard C \& Tremblay A (1998) Dietary fat composition and human adiposity. European Journal of Clinical Nutrition 52, 2-6.

Food and Agriculture Organization/World Health Organization/ United Nations University (1985) Energy and Protein Requirements. Geneva: WHO.

Flatt JP (1987) Dietary fat, carbohydrate balance and weight maintenance: Effects of exercise. American Journal of Clinical Nutrition 45, 296-306.
Frazao E (1999) High costs of poor eating patterns in United States. In America's Eating Habits: Changes and Consequences, AIB no 750, pp. 5-32. Washington, DC: US Department of Agriculture, Economic Research Service.

Guthrie JF, Derby BM \& Levy AS (1999) What people know and do not know about nutrition. In America's Eating Habits: Changes and Consequences, AIB no 750, pp. 243-280. Washington, DC: US Department of Agriculture, Economic Research Service.

James WPT \& Schofield E (1990) Human Energy Requirements. Oxford: Oxford University Press.

Jones P, Hunt M, Brown T \& Norgan N (1986) Waist-hip circumference ratio and its relation to age and overweight in British men. Human Nutrition: Clinical Nutrition 40C, 239-247.

Kristal AR, Feng Z, Coates RJ, Oberman A \& George V (1997) Associations of race/ethnicity, education and dietary intervention with the validity and reliability of a food frequency questionnaire. American Journal of Epidemiology 146, 856-869.

Laird N \& Ware J (1982) Random effects models for longitudinal data. Biometrics 38, 963-974.

Larsson B, Svardsudd K, Welin K, Wilhemsen L, Bjorntorp P \& Tibblin G (1984) Abdominal adipose tissue distribution, obesity and risk of cardiovascular disease and death: 13 year follow up of participants in the study of men born in 1913. Clinical Research 288, 1401-1404.

Nelson M, Black AE, Morris JA \& Cole TJ (1989) Between-andwithin subject variation in nutrient intake from infancy to old age: Estimating the number of days to rank dietary intakes with desired precision. American Journal of Clinical Nutrition 50, $155-167$.

Prentice A (1995) Obesity in Britain: Gluttony or sloth? British Medical Journal 311, 437-439.

Rexrode KM, Carey VJ, Hennekens CH, Walters EE, Colditz GA, Stampfer MJ, Willett WC \& Manson JE (1999) Abdominal adiposity and coronary heart disease in women. Journal of American Medical Association 280, 1843-1848.

Rolls BJ, Bell EA, Castellanos VH, Chow M, Pelkman CL \& Thorwart ML (1999) Energy density but not fat content of foods affected energy intake in lean and obese women. American Journal of Clinical Nutrition 69, 863-871.

Schutz Y, Flatt J-P \& Jequier E (1989) Failure of dietary fat intake to promote fat oxidation: A factor favoring the development of obesity. American Journal of Clinical Nutrition 50, 307-314.

Shepard TY, Weil KM, Sharp TA, Grunwald GK, Bell ML, Hill JO \& Eckel RH (2001) Occasional physical inactivity and a high-fat diet may be important in the development and maintenance of obesity in human subject. American Journal of Clinical Nutrition 73, 703-708.

Sheppard L, Kristal A \& Kushi L (1991) Weight loss in women participating in a randomized trial of low-fat diets. American Journal of Clinical Nutrition 54, 821-828.

Smith SR, de Long L, Zachwieja JJ, Nguyen T, Rood J, Windhauser M, Volaufova J \& Bray GA (2000) Concurrent physical activity increases fat oxidation during shift to a high-fat diet. American Journal of Clinical Nutrition 72, 131-138.

United States Department of Agriculture/Department of Health and Human Services (1990) Nutrition and Your Health: Dietary Guidelines for Americans. Washington, DC: DHHS.

United States Department of Agriculture/Department of Health and Human Services (2000) Nutrition and Your Health: Dietary Guidelines for Americans, 5th ed. Washington, DC: DHHS.

Willett W (1998a) Is dietary fat a major determinant of body fat? American Journal of Clinical Nutrition 67, 556S-562S.

Willett W (1998b) Nutritional Epidemiology, 2nd ed. Oxford: Oxford University Press. 